\title{
Etiologies of Fever of Unknown Origin in HIV/AIDS Patients, Hanoi, Vietnam
}

\section{Kim Thu Nguyen ( $\nabla$ nguyenkimthu@hmu.edu.vn )}

Hanoi Medical University

\section{Hai Yen Nguyen}

Hanoi Medical University

\section{Thi Hao Nguyen}

National Hospital for Tropical Diseases

\section{Minh Quang Khong}

National Hospital for Tropical Diseases

Kim Ngoc Tran

Hanoi Medical University

\section{Research Article}

Keywords: Fever of origin unknown, HIV/AIDS patients, CD4 T cell count, Vietnam.

Posted Date: July 19th, 2021

DOl: https://doi.org/10.21203/rs.3.rs-668643/v1

License: (c) (1) This work is licensed under a Creative Commons Attribution 4.0 International License. Read Full License

Version of Record: A version of this preprint was published at BMC Infectious Diseases on January 18th, 2022. See the published version at https://doi.org/10.1186/s12879-022-07049-3. 


\section{Abstract}

Background: Prolonged fever is a challenge for clinicians in managing patients with HIV/AIDS. Their TCD 4 counts can be helpful in the diagnosis and treatment. This study aimed to determine several common etiologies of prolonged fever and their distribution in different TCD4 count levels in HIV/AIDS patients.

Methods: A cross-sectional, retrospective and prospective study was conducted on 195 HIV/AIDS patients with fever of unknown origin admitted to National Hospital for Tropical Diseases from January 2016 to June 2019. Clinical parameters, immune status, and etiologies for each patient were recorded. Odds ratio was used to compare the distribution of common etiologies in two different TCD4 count levels, including $<50$ cells $/ \mathrm{mm}^{3}$ and $\geq 50$ cells $/ \mathrm{mm}^{3}$.

Results: The proportion of opportunistic infections and non-infectious etiologies was $93.3 \%$ and $3.6 \%$, respectively. Tuberculosis was the most common opportunistic infection (46.7\%), followed by Talaromycosis (29.2\%) and Pneumocystis jiroveci (20.5\%). Tuberculosis was predominant in all stratified CD4 levels. Most cases with Talaromycosis had CD4 counts below 50 cells $/ \mathrm{mm}^{3} .53 .8 \%$ of cases were infected by one pathogen. There was no difference between the number of concurrent etiologies and TCD4 levels.

Conclusions: Opportunistic infections, especially tuberculosis, are still the leading cause of prolonged fever in HIV/AIDS patients. Talaromyces marnefei should be screened in patients with CD $4<50$ cells/mm3. This study implies that guidelines regarding providing the appropriate treatment for FUO-HIV patients based on the CD 4 cells count should be developed that may reduce the burden of clinicians in managing HIV/AIDS patients.

\section{Background}

Prolonged fever is a common symptom in people living with human immunodeficiency virus (HIV) and acquired immune deficiency syndrome (AIDS), particularly in those diagnosed with advanced stages (1). Fever of unknown origin (FUO) is divided into four groups, including (a) classic FUO by definition of Petersdorf and Beeson in 1961; (b) FUO in hospital; (c) FUO associated with leukopenia and (d) FUO associated with HIV (2). According to the World Health Organization (WHO), there were 38 million people living with HIV and 1.7 million people newly infected HIV in 2019 globally (3). The rates of FUO among HIV-infected persons varied in several previous studies, with a wide range of 3.4\%-21.0\% (4-7). In Vietnam, HIV/AIDS is a major public health problem, and the leading health burden nationwide. As of 2020 , there were 213,724 people living with HIV and 13,955 people newly infected HIV (8).

Since the development of testing techniques in recent years, more causes of long-lasting fever among HIV patients have been identified $(9,10)$. Several studies in developing countries indicated that opportunistic infections such as infections due to Leishmania species or Mycobacterium tuberculosis might lead to prolonged fever among people living with $\operatorname{HIV/AIDS}(1,9)$. In another study conducted in a 
nation of Southeast Asian region, Thailand, Mycobacterium tuberculosis was the most frequent infectious etiology, followed by Cryptococcus neoformans and Pneumocystis jiroveci (10).

Furthermore, the prevalence of etiology causing prolonged fever in HIV-infected patients depends on their immune deficiency status which is reflected by the CD4 cell count (1). The previous study reported that $77.0 \%$ of FUO-HIV patients had the CD4 cells count fewer than 100 cells $/ \mathrm{mm} 3$ (4). Thus, CD4 cell counts could be useful in predicting common pathogens causing prolonged fever in patients infected with HIV. Despite advances in diagnostic methods to identify pathogens, making diagnoses of pathogens causing prolonged fever in HIV-infected patients remains a challenge.

However, the information on HIV-related long-lasting fever in Vietnam has been limited. Therefore, to have more insightful knowledge about the association between pathogens and immune status in patients with HIV/AIDS in Vietnam, this study aimed to examine several common causes of FUO and investigate the association between some common etiologies causing prolonged fever in HIV infected patients and their immune status.

\section{Methods}

\section{Study design and setting}

A cross-sectional, retrospective and prospective study was performed in the National Hospital for Tropical Diseases from January 2016 to June 2019. Medical records of patients were collected with specific criteria as follows (1) age $\geq 18$ years, (2) being infected HIV, confirmed by three testing methods as approved by the Ministry of Health, and (3) having prolonged fever defined as armpit temperature from $38,3^{\circ} \mathrm{C}$ lasting at least 3 weeks. Exclusion criteria included patients whose in-hospital duration was too short to make the diagnosis.

For the retrospective study, all medical records of HIV/AIDS hospitalizing from January 2016 to June 2018 were collected. There were 170 eligible patients included in the study. For the prospective study, HIV/AIDS patients treated in National Hospital for Tropical Diseases from July 2018 to June 2019 were included in the study. After applying purposive sampling, the total sample size was estimated as 195 participants. We collected their personal information from their medical records, including (1) reasons for hospitalization, (2) history of antiretroviral therapy (ART) treatment and clinical manifestation, and (3) laboratory tests (routine tests, CD4 cells count, chest - $\mathrm{x}$-ray and abdominal ultrasound, specific tests for identifying etiologies, other examinations, and diagnostic tests to support causative diagnoses, and bone marrow aspiration or biopsy if patients had abnormal complete blood count (CBC)).

\section{Study definitions and observed methods}

Fever of unknown origin (FUO) was defined as body temperature over $38.3^{\circ} \mathrm{C}\left(101^{\circ} \mathrm{F}\right)$ for more than three weeks without a clear diagnosis despite three days of investigations in the hospital (2). A case was defined as being infected opportunistic infection if there was at least one isolated pathogen. A patient 
was diagnosed with bloodstream infection if there was at least a positive blood culture and systemic inflammatory response syndrome. A case was defined as being suffered a non-infectious condition if there was at least one confirmed non-infectious cause such as hematologic diseases, malignancies, autoimmune diseases,... All patients were evaluated in clinical stages and immune stages then identified causes of fever. CD4 cell count was divided into two levels that were $<50$ cells $/ \mathrm{mm}^{3}$ and $\geq 50$ cells $/ \mathrm{mm}^{3}$ to investigate the association with causes of prolonged fever.

Appropriate diagnostic investigations were based on the clinical presentations, initial laboratory and radiographic data. HIV status was confirmed by three positive tests, including Enzyme-linked immunosorbent assay (ELISA), SD Bioline HIV 1/2, and Vikia HIV 1/2. The etiological detections were performed according to the standard testing procedures of the National Hospital for Tropical Diseases. The etiologies causing FUO consist of opportunistic infections and non-infectious causes.

\section{Data analysis and statistical methods}

To address the aims of the study, both descriptive and analytical statistics were analyzed by using SPSS software version 20.0. Qualitative variables were presented as frequency and percentage (\%), while quantitative variables were presented as mean and standard deviation (SD). Comparisons between categorical variables were tested by Chi-square and Fisher's exact test. Crude odds ratio (OR) and 95\% confident interval $(95 \% \mathrm{Cl})$ were used to determine several common etiologies causing prolonged fever among HIV-infected patients associated with their level of CD4 count. A p-value $(p)<0.05$ was considered statistically significant.

\section{Results}

The majority of participants was male patients that accounted for $75.4 \%$ (Table 1 ). The male/female ratio was 3:1. The mean age was 37.5 years (SD: \pm 8.5 years), in which half of the total of study subjects was in working age (31-40 years). The mean of duration was $4.3 \pm 2.2$ weeks. At presentation of FUO, 23 patients $(11.8 \%)$ were in the stage I-III while 172 patients $(88.2 \%)$ were in the stage IV. The median of CD4 T cell counts was 19 cells $/ \mathrm{mm} 3$, with a wide range from 1 to 713 cells $/ \mathrm{mm} 3.35 .9 \%$ of patients were currently on ART.

Opportunistic infections accounted for $93.3 \%$ of 195 HIV-infected cases with a fever of unknown origin (Table 2). Tuberculosis was the most common opportunistic infection (46.7\%), followed by Talaromycosis (PM) (29.2\%) and Pneumocystis jiroveci (PCP) infection (20.5\%). Less common pathogens for opportunistic infections included bacterial pneumonia (11.3\%), Cytomegalovirus (CMV) (10.3\%), sepsis (10.3\%), Toxoplasma (5.6\%), Cryptococcus (2.6\%) and Mycobacteria avium complex (MAC) (1.0\%). These findings reported 7 cases with non-infectious causes (3.6\%) and 6 undefined cases (3.1\%). For co-infection, $53.8 \%$ of cases were infected by one pathogen, followed by two pathogens (38.0\%) and three pathogens (8.2\%). 
Table 3 demonstrates the prevalence of etiologies by CD4 count levels. Tuberculosis was predominant in all subgroups by stratified CD4 levels. Most of cases with other opportunistic infections (Talaromycosis, PCP infection, Bacterial pneumonia, Septicemia, Cytomegalovirus, and Toxoplasmosis) had CD4 counts $<50$ cells $/ \mathrm{mm} 3$. Besides, CD 4 count $<50$ cells $/ \mathrm{mm} 3$ was reported in all cases with either Cryptococcus infection or MAC infection. The differences in some opportunistic infections such as Tuberculosis, Talaromycosis, Septicemia between two levels of CD4 were statistically significant. Additionally, there was no significant difference between the number of pathogens in co-infections and TCD4 levels.

Table 4 shows crude OR of two levels of T-CD4 count in several opportunistic infections and coinfection to determine their association. Compared to patient with T-CD $4<50$ cells $/ \mathrm{mm} 3$, those having T-CD $4 \geq 50$ cells $/ \mathrm{mm} 3$ was $2.31(95 \% \mathrm{Cl}: 1.14,4.75 ; \mathrm{p}$-value $=0.012$ ) times higher to infect with Tuberculosis. On the other hand, individual having T-CD4 $\geq 50$ cells $/ \mathrm{mm} 3$ was $0.44(95 \% \mathrm{Cl}: 0.18,1.03$; $\mathrm{p}$-value $=0.043)$ times less likely to have Talaromycosis than those having T-CD4 count $<50$ cells $/ \mathrm{mm} 3$. These differences were statistically significant. For PCP, bacterial pneumonia, and coinfections ( $>2$ pathogens), there was no statistically significant difference between two groups of T-CD 4 cells count.

\section{Discussion}

In this study, opportunistic infections frequently occurred among HIV patients having FUO in which Tuberculosis was the most common infection, followed by Talaromycosis and PCP. The majority of FUOHIV patients were infected by a pathogen. In addition, the difference in some opportunistic infections (Tuberculosis, Talaromycosis, Septicemia), and non-infections (non-Hodgkin lymphoma) between two levels of CD 4 count was statistically significant.

Among 195 HIV-infected patients with prolonged fever, the percentage of males was three-fold higher than that of females ( $75.4 \%$ and $24.6 \%$, respectively). This result was similar to the results of a study in Thailand $(61.0 \%$ and $39.0 \%$, respectively) $(10)$, and a previous study in Vietnam $(76.8 \%$ and $23.2 \%$, respectively) (11).

Prolonged fever is a common symptom in HIV-infected people, especially in those with advanced disease. In this study, the median number of T-CD 4 cells was $19 \mathrm{cells} / \mathrm{mm} 3$, with the interquartile range (IQR) of 8-50. The T-CD4 lowest number was $1 \mathrm{cell} / \mathrm{mm} 3$ and the highest one was $713 \mathrm{cells} / \mathrm{mm} 3$. Approximately $74.3 \%$ of patients had T-CD 4 count below 50 cells $/ \mathrm{mm} 3$ and the majority of patients were in clinical stage IV (88.2\%). The study in Thailand on HIV-infected patients with prolonged fever also showed that the average T-CD 4 count was 56 cells $/ \mathrm{mm} 3$ (12) that was similar to that in our study (49.7 cells $/ \mathrm{mm} 3$ ). In addition, the study indicated that the median was $30 \mathrm{cell} / \mathrm{sm} 3$, the highest number was $500 \mathrm{cell} / \mathrm{s} / \mathrm{mm}$, the lowest is 0 cells/mm3 (12). Thus, HIV-infected patients with prolonged fever usually had serious immunodeficiency status. 
The fever was primarily related to opportunistic infections and sometimes with malignancies.

Opportunistic infections depend on the immunodeficiency status of HIV-infected people, local circulating diseases, the primary and secondary prophylaxis (13). This study identified that the infectious etiologies accounted for the highest proportion (93.3\%) that was similar to that in a study performed in the US (2007) on HIV infected patients with prolonged fever, with the proportion of opportunistic infections of $90.6 \%$ (14). Another research conducted in Thailand showed that 71/90 HIV-infected patients $(78.9 \%)$ identified the cause of prolonged fever, $70 / 71$ patients (98.6\%) were caused by infectious etiology, and $1 / 71$ patients $(1.4 \%)$ with non-infectious etiology (15).

Among the infectious etiologies of prolonge fever in HIV-infected patients, tuberculosis accounted for the highest proportion, followed by Talaromycosis and PCP; less common causes consisted of bacterial pneumonia, CMV, sepsis, toxoplasmosis, and Cryptococcus. The prevalence of tuberculosis in the study was similar to some studies in regional countries as well as in the world $(10,16)$. This result may be explained by the fact that HIV has injured the body's immune system through T-CD4, T-CD8, macrophages, thus making TB bacteria survive, reactivate latent tuberculosis and spread of tuberculosis bacteria are higher than other organisms (17). This finding indicated that $41.4 \%$ of patients $(60$ individuals) had T-CD4 below 50 cells/mm3 accounted for the highest proportion. The difference in the incidence of tuberculosis was statistically significant between the two groups of T-CD $4<50$ and $\geq 50$ cells/mm3. The prevalence of Talaromycosis infection in our study (29.2\%) was greater than that in a study in Northern Thailand (17.8\%) (15). Talaromyces fungus grows in tropical regions, especially in Southeast Asia where the climate is hot and humid. In addition to humans, bamboo rats are natural hosts for Talaromyces, which are also found in this area (18).

Additionally, 48/57 patients diagnosed with PM infection had T-CD $4<50$ cells $/ \mathrm{mm} 3$. The difference in the incidence of PM was statistically significant between the two groups of T-CD $4<50$ cells $/ \mathrm{mm} 3$ and $\geq 50$ cells/mm3. This result was similar to the studies in Thailand (10). Thus, according to the Ministry of Health classification for the T-CD4 cells count, most patients are in the AIDS stage. This finding reflects the clinical manifestation of patients in the study.

Furthermore, PCP-associated pneumonia was the third most common cause that was similar to that in Thailand (13.0\%) (10), and in the United States (13.0\%) (9). The research showed that PCP was a common cause of prolonged fever and was a common cause of pneumonia in HIV-infected patients. Therefore, when in HIV-infected patients with prolonged fever who have respiratory diseases, the two most common causes were tuberculosis and PCP.

Another finding of the study showed that CMV was an uncommon infectious cause of prolonged fever in HIV-infected patients that was similar to a previous study (13). CMV was a type of opportunistic infections with the rate varied by gender, age, socioeconomic status, and geographic location $(19,20)$. Worldwide, the lowest rate of CMV was in Western Europe and the United States, the highest in South America, Africa, and Asia, often among non-white ethnic minorities and in low-income countries (20). 
No patients in the study with Cryptococcus, CMV, sepsis, toxoplasmosis, MAC had T-CD4 > 100 cells/mm3. In Pertel's study, CMV disease was more common in patients with T-CD4 > 100 cells/mm3, the risk of CMV increased when T-CD4 count dropped below 100 cells/mm3 and increased significantly at TCD4 $<50$ cells/mm3 (21).

All patients infected with Cryptococcus belonged to the T-CD 4 group $<50$ cells $/ \mathrm{mm} 3$. This result was different from that in Thailand in which most patients with T-CD $4<50$ cells $/ \mathrm{mm} 3$ were 1.16 times higher than those of T-CD4 > 50 cells/mm3 [61]. According to Renold and colleagues, 75.0\% of brain toxoplasmosis patients have T-CD4 < 100 cells/mm3, and the T-CD4 average was 78 cells/mm3 (22). Thus, CMV and Cryptococcus infection were opportunistic conditions occurring during the period of severe immunodeficiency, commonly in patients with a T-CD4 count $<50$ cells/mm3.

For non-infectious etiology, non-Hodgkin lymphoma was a commonly mentioned cause in the studies. In this study, the proportion of non-Hodgkin lymphoma patients (1.5\%) was lower than that in the Jose Mayo's study (4.2\%) (23) and Danai Kitkungvan's study (4.0\%) (10). In addition, the study also noted that HLH was a non-infectious cause of prolonged fever in HIV patients. In non-infectious etiology, NonHodgkin lymphoma was found at all T-CD4 count levels.

In severe immunodeficiency HIV patients with very low T-CD4, prolonged fever might be caused by two or more concomitant etiologies. In the study, the proportion of patients having an etiology (53.8\%)

accounted for half of all patients, followed by two and three etiologies (38.0\% and $8.2 \%$, respectively) that differed to those in other studies. In the study in Thailand, 73.6\% of patients had an infectious etiology and $26 \%$ of patients had 2 or more co-infected pathogens (10). According to a study by Romanee Chaiwarith, $81.7 \%$ of patients had an etiology, and $18.3 \%$ of those had 2 or more concurrent etiologies (15). Another study in Spain showed that $84.2 \%$ of patients had an etiology, $12.5 \%$ of patients had 2 etiologies and $3.3 \%$ of patients had 3 or more concomitant etiologies (5). In the Bissuel's study, $83.7 \%$ of patients had an etiology, $16.3 \%$ had 2 or more etiologies (4). In the Lambertucci's study, $81.8 \%$ of patients had an etiology (24). However, these findings indicated that there was no difference between the number of concurrent etiologies and T-CD4 levels.

This study had a few limitations. First, the retrospective design might provide insufficient data that might lack of clinical information for the aims of study. Thus, the combination with prospective study and the application of purposive sampling may be sufficient to have the comprehensive picture of the studied issue. Second, since the study was conducted only at a hospital in the North region of Vietnam, participants might not represent the general population in Vietnam. Further study should be performed at more hospitals in other regions of Vietnam.

\section{Conclusion}

In a study of 195 cases of prolonged fever in HIV/AIDS patients in Vietnam, opportunistic infections, especially tuberculosis, were the leading cause of fever of unknown origin in HIV/AIDS patients.

Screening for T. marnefei should be recommended for patients with CD $4<50$ cells/mm3. Since most of 
identified etiologies causing FUO are diagnosable and treatable, this study implies that guidelines and recommendations for the management of prolonged fever in HIV-infected patients based on the levels of CD4 should be developed to provide the appropriate treatment for FUO-HIV individuals.

\section{Abbreviations}

ART: Antiretroviral therapy; AIDS: Acquired immune deficiency syndrome; CBC: Complete blood count; HIV: Human immunodeficiency virus; FUO: Fever of unknown origin;

\section{Declarations}

\section{Ethics approval and consent to participate}

This study was approved by the Institutional Review Board at National Hospital for Tropical Diseases, Hanoi, Vietnam, which waived the need for obtaining consent from the patients. All personal identifiers were anonymized for confidentiality before data processing was performed. This research was in compliance with the Helsinki Declaration.

\section{Consent for publication}

Not Applicable.

\section{Availability of data and materials}

The datasets used and analyzed during the current study are available from the corresponding author on reasonable request.

\section{Competing interests}

The authors declare that they have no competing interests.

\section{Funding}

Not Applicable.

\section{Authors' contributions}

KTN and HYN was responsible for conception, design and quality control of this study. HYN, THN, MQK, and KNT worked on the analysis and interpretation of the data. KTN, HYN and KNT drafted the manuscript. KTN and KNT revised the manuscript. All authors read and approved the final manuscript.

\section{Acknowledgement}

Not Applicable. 


\section{References}

1. Jung AC, Paauw DS. Diagnosing HIV-related disease: using the CD4 count as a guide. J Gen Intern Med. 1998;13(2):131-6.

2. Durrack DT, Street AT. Fever of unknown origin reexamined and redefined. Current Clin Tropical Infect Dis. 1991;11:35-51.

3. Organization WH. HIV/AIDS: fact sheet 2019 [Available from: https://www.who.int/en/news-room/factsheets/detail/hiv-aids.

4. Bissuel F, Leport C, Perronne C, et al. Fever of unknown origin in HIV-infected patients: a critical analysis of a retrospective series of 57 cases. J Intern Med. 1994;236(5):529-35.

5. Lozano F, Torre-Cisneros J, Bascunana A, al e. Prospective evaluation of fever of unknown origin in patients infected with the human immunodeficiency virus. Grupo Andaluz para el Estudio de las Enfermedades Infecciosas. Eur J Clin Microbiol Infect Dis 1996;15(9):705-11.

6. Miller RF, Hingorami AD, Foley NM. Pyrexia of undetermined origin in patients with human immunodeficiency virus infection and AIDS. International journal of STD \& AIDS. 1996;7(3):170-5.

7. Miralles P, Moreno S, Pérez-Tascón M, Cosín J, Díaz MD, Bouza E. Fever of uncertain origin in patients infected with the human immunodeficiency virus. Clin Infect Dis. 1995;20(4):872-5.

8. Health VMo. Report for HIV/AIDS Prevention and Control 2020. Administration of HIV/AIDS Control; 2021.

9. Armstrong W.S, Katz J.T, Kazanjian P.H. Human Immunodeficiency Virus-Associated Fever of Unknown Origin: A Study of 70 Patients in the United States and Review. Clinical Infectious Diseases. 1999;28(2):341-5.

10. Kitkungvan $D$, Apisarnthanarak A, Plengpart $P$, Mundy LM. Fever of unknown origin in patients with HIV infection in Thailand: an observational study and review of the literature. International journal of STD \& AIDS. 2008;19(4):232-5.

11. Nguyen Tien Lam, Et al. Etiologies of opportunistic infections among HIV/AIDS inpatient at National Hospital for Tropical Diseases. Journal of Practical Medicine. 2010;781:135-8.

12. Romanee Chaiwarith, Khuanchai Supparatpinyo, Suchart Punjaisee, Vilai Kotarathititum, Thira Sirisanthana. Prolonged Fever in Human Immunodeficiency VirusInfected Adult Patients in Northern Thailand. J Infect Dis Antimicrob Agents. 2005;22(3):103-10.

13. Florence E, Bottieau E, Lynen L, Colebunders R. Patients with HIV infection and fever: a diagnostic approach. Acta Clin Belg. 2002;57(4):184-90. 
14. Hot A, Schmulewitz L, Viard JP, Lortholary O. Fever of unknown origin in HIV/AIDS patients. Infectious disease clinics of North America. 2007;21(4):1013-32, ix.

15. Romanee Chaiwarith MD, Khuanchai Supparatpinyo, M.D.*, Suchart Punjaisee, Ph.D.**. Vilai Kotarathititum, R.N.*, Thira Sirisanthana, M.D.*. Prolonged Fever in Human Immunodeficiency VirusInfected Adult Patients in Northern Thailand. J INFECT DIS ANTIMICROB AGENTS. 2005;22(3):10310.

16. S. Anuradha, Sandeep Ghosh, Richa Dewan, Ravinder Kaur, K. Rajeshwari. Fever of Unknown Origin (FUO) in HIV Infection in the Era of Antiretroviral Treatment (ART) in India: Development of a Simple Diagnostic Algorithm. BJMMR. 2015;7(10):839-46.

17. Pawlowski A, Jansson M, Sköld M, Rottenberg ME, Källenius G. Tuberculosis and HIV Co-Infection. PLoS Pathogens. 2012;8(2):e1002464.

18. Vanittanakom N, Cooper C.R, Fisher M.C, Sirisanthana T. Penicillium marneffei Infection and Recent Advances in the Epidemiology and Molecular Biology Aspects. Clinical Microbiology Reviews. 2006;19(1):95-110.

19. Rubaihayo J, Tumwesigye NM, Konde-Lule J, Wamani H, Nakku-Joloba E, Makumbi F. Frequency and distribution patterns of opportunistic infections associated with HIV/AIDS in Uganda. BMC Res Notes. 2016;9(1):501-.

20. Ben-Smith A, Gorak-Stolinska P, Floyd S, et al. Differences between naïve and memory T cell phenotype in Malawian and UK adolescents: a role for Cytomegalovirus? BMC infect Dis. 2008;8:139.

21. Pertel P, Hirschtick R, Phair J, et al. Risk of developing cytomegalovirus retinitis in persons infected with the human immunodeficiency virus. J Acquir Immune Defic Syndr. 1998;5:1069-74.

22. Renold C, Sugar A, Chave J, et al. Toxoplasma encephalitis in patients with the acquired immunodeficiency syndrome. Medicine (Baltimore). 1998;71(4):224-39.

23. Mayo J, Collazos J, Martinez E. Fever of unknown origin in the HIV-infected patient: new scenario for an old problem. Scand J Infect Dis. 1997;29(4):327-36.

24. Richards FO Jr, Kovacs JA, Luft BJ. Preventing toxoplasmic encephalitis in persons infected with human immunodeficiency virus. Clinical Infectious Diseases,. 1995;21(supplement 1):549-56.

\section{Tables}

Table 1: Characteristics of participants $(\mathrm{N}=195)$ 


\section{Gender (\%)}

Men

$147(75.4)$

Women

48 (24.6)

Age (Meantsd; years)

$37.5 \pm 8.5$

Duration of fever (Meantsd; weeks)

$4.3 \pm 2.2$

Clinical stages

Stage I-III (\%)

23 (11.8)

Stage IV (\%)

$172(88.2)$

T-CD4 count (Mean \pm sd; cells $/ \mathbf{m m} 3$ )

$49.7 \pm 99.3$

$<50(\%)$

145 (74.4)

$\geq 50(\%)$

$50(25.6)$

Currently on ART (\%)

No

125 (64.1)

Yes

$70(35.9)$

Table 2: Prevalence of etiologies 


\begin{tabular}{|ll|}
\hline Etiologies & $\mathbf{n}(\%)$ \\
\hline Total & $195(100)$ \\
\hline Opportunistic infections & $183(93.9)$ \\
\hline Tuberculosis (TB) & $91(46.7)$ \\
\hline Talaromycosis (PM) & $57(29.2)$ \\
\hline Pneumocystis jiroveci infection (PCP) & $40(20.5)$ \\
\hline Bacterial pneumonia & $22(11.3)$ \\
\hline Cytomegalovirus (CMV) & $20(10.3)$ \\
\hline Septicemia & $20(10.3)$ \\
\hline Toxoplasmosis & $11(5.6)$ \\
\hline Cryptococcosis & $5(2.6)$ \\
\hline Mycobacteria avium complex infection (MAC) & $2(1.0)$ \\
\hline Non-infectious causes & $7(3.6)$ \\
\hline Hemophagocytic lymphohistiocytosis (HLH) syndrome & $4(2.1)$ \\
\hline Non-Hodgkin Lymphoma & $3(1.5)$ \\
\hline Undefined causes & $6(3.1)$ \\
\hline Coinfection & $105(53.8)$ \\
\hline 1 pathogen & $74(38.0)$ \\
\hline 2 pathogens & $16(8.2)$ \\
\hline 3 pathogens & \\
\hline
\end{tabular}

Table 3: Prevalence of etiologies by levels of CD4 count 


\begin{tabular}{|c|c|c|c|}
\hline & \multicolumn{2}{|c|}{ Levels of CD4 count } & \multirow[b]{2}{*}{ p-value } \\
\hline & $\begin{array}{c}<50 \text { cells } / \mathrm{mm} 3 \\
\mathrm{n}(\%)\end{array}$ & $\begin{array}{c}\geq 50 \text { cells } / \mathrm{mm} 3 \\
\mathrm{n}(\%)\end{array}$ & \\
\hline Total & $145(100)$ & $50(100)$ & \\
\hline Opportunistic infections & $138(95.2)$ & $45(90.0)$ & 0.19 \\
\hline Tuberculosis & $60(41.4)$ & $31(62.0)$ & 0.012 \\
\hline Talaromycosis & $48(33.1)$ & $9(18.0)$ & 0.048 \\
\hline PCP infection & $30(20.7)$ & $10(20.0)$ & 0.92 \\
\hline Bacterial pneumonia & $18(12.4)$ & $4(8.0)$ & 0.60 \\
\hline Septicemia & $19(13.1)$ & $1(2.0)$ & 0.03 \\
\hline Cytomegalovirus & $16(11.0)$ & $4(0.1)$ & 0.54 \\
\hline Cryptococcosis & $5(3.5)$ & $0(0.0)$ & 0.33 \\
\hline $\mathrm{MAC}$ infection & $2(1.4)$ & $0(0.0)$ & 1.00 \\
\hline Toxoplasmosis & $7(4.8)$ & $4(8.0)$ & 0.48 \\
\hline Non-infectious causes & $3(2.1)$ & $4(8.0)$ & 0.05 \\
\hline Hemophagocytic & $1(0.7)$ & $3(6.0)$ & 0.05 \\
\hline \multicolumn{4}{|l|}{ lymphohistiocytosis $(\mathrm{HLH})$} \\
\hline \multicolumn{4}{|l|}{ syndrome } \\
\hline Non-Hodgkin Lymphoma & $2(1.4)$ & $1(50.0)$ & 0.04 \\
\hline \multicolumn{4}{|l|}{ Coinfection } \\
\hline 1 pathogen & $79(54.5)$ & $26(52.0)$ & 0.72 \\
\hline 2 pathogens & $53(36.5)$ & $21(42.0)$ & \\
\hline 3 pathogens & $13(9.0)$ & $3(6.0)$ & \\
\hline
\end{tabular}

Table 4: Crude OR of several common etiologies

\begin{tabular}{lccc}
\hline & \multicolumn{2}{c}{ Levels of CD4 count } & \multirow{2}{*}{ p-value } \\
\cline { 2 - 3 } & \multicolumn{20}{c}{ cells $/ \mathrm{mm} 3$} & $\geq 50$ cells $/ \mathrm{mm} 3$ & \\
\hline Tuberculosis & 1.00 & $\mathbf{2 . 3 1}(\mathbf{1 . 1 4}, \mathbf{4 . 7 5})$ & $\mathbf{0 . 0 1 2}$ \\
Talaromycosis & 1.00 & $\mathbf{0 . 4 4}(\mathbf{0 . 1 8}, \mathbf{1 . 0 3})$ & $\mathbf{0 . 0 4 3}$ \\
PCP infection & 1.00 & $0.96(0.38,2.24)$ & 1.00 \\
Bacterial pneumonia & 1.00 & $0.61(0.14,2.00)$ & 0.39 \\
Coinfection $(>2$ pathogens $)$ & 1.00 & $0.91(0.45,1.82)$ & 0.76 \\
\hline
\end{tabular}

